\title{
The LEAP (Learning Excellence Achievement Pathway) framework: A model for student learning development in higher education
}

\section{Emily McIntosh}

University of Bolton, UK

Mary E. Barden

University of Bolton, UK

\section{Abstract}

This article explores the development of the LEAP (Learning Excellence Achievement Pathway) framework at the University of Bolton, UK. It describes the nature of the project and focuses on the methodology involved in conducting an institution-wide audit of student learning development (LD) provision and producing a visual framework to stimulate a culture of LD within the organisation. Whilst most UK universities offer a student LD programme at undergraduate level, little work has been undertaken to develop and define a visual framework which underpins these programmes and assists students to conceptualise their progress. This paper explores the context for creating an LD framework and outlines how LD provision is mapped to align curricular LD opportunities with co-curricular student engagement initiatives. The article then considers the implementation of the LEAP framework. A mixed-methods evaluation activity was conducted, involving both staff and students, using a variety of data. Evaluation methods were used to assess the impact of the framework on student LD, revealing a number of positive changes to their LD behaviour and habits, their assessment of LD, the accessibility of help and support and their awareness of the context in which LD takes place. Finally, we identify future developments to the framework to embed it further within the institution.

Keywords: learning development framework; digital literacy; academic development; learning development culture; digital badging; student engagement. 


\section{Introduction}

Higher education (HE) is changing rapidly. The introduction of the Teaching Excellence Framework (TEF), enshrined in the Higher Education and Research Act (HERA, 2017), places a firm focus on metrics to quantify student retention, success and employability. The Dearing Report (NCIHE, 1997) argued that students need to become more selfdirected and identified that students require support to develop the skills necessary to succeed in HE. In 2009, Gibbs offered a conceptual map of learning development (LD) and identified the need for students to develop the ability 'to cope with the challenging intellectual and academic demands they face, and to develop their sophistication as learners within their academic disciplines' (Gibbs, 2009, p.2). Almost ten years on, student learning development, that is curricular and co-curricular skills activities, has gained in importance. Indeed, LD is now a key part of the student experience (Hilsdon, 2011).

LD initiatives offer students the opportunity to explore skills and competencies, and help them make sense of academic and professional practices, as well as reflecting on their progress and identifying future actions. Most UK universities offer a student LD programme at undergraduate level but little work has been undertaken to develop and define a framework which underpins and champions these programmes, providing adequate visibility for them across the organisation. Reedy and Goodfellow (2014, pp.1-2) endorse the European E-Learning Programme's definition of an educational framework as:

a rational structure that organises institutional assumptions, curriculum objectives, educational concepts, ethical values, technologies, pedagogical goals and constraints, and professional practices, in order to implement educational policies.

We extend this definition, and apply it to LD practice in HE specifically, to propose that an LD framework is one which integrates and combines curricular and co-curricular developmental activities to structure, scaffold, champion, highlight and embed student LD in all its forms. Here, we define curricular LD activity as that which takes place within traditional academic teaching and learning environments. This includes capturing the experiences that happen within lectures, seminars, Virtual Learning Environments (VLEs), live briefs, and placements. Co-curricular activity is defined as equally central to student LD and captures any activity, whether it be peer learning, volunteering, or participation in 
clubs and societies, that encourages students to apply their skills and experiences in practice, forming a central part of their development as learners. We argue that a student LD framework should be collaborative and involve the whole institution; its success should be measured in the provision of inclusive, high-quality LD activities, delivered and embedded across recognised institutional and disciplinary boundaries. An LD framework should encourage autonomous and deep learning strategies and support students to become lifelong learners, indeed, 'Citizen Scholars' (Arvanitakis and Hornsby, 2016). In terms of student outcomes, students who engage in LD activities should not only value the acquisition of disciplinary knowledge and skills, but also apply these in various contexts. The impact of this approach on student outcomes, employability and the pursuit of further study should also be significant.

This paper outlines the design and development of the LEAP (Learning Excellence Achievement Pathway) framework at the University of Bolton, UK. The LEAP framework was developed over a period of twelve months and launched formally in September 2017. The paper describes the institutional project and the methodology involved in designing, developing and launching the LEAP framework and evaluates its initial impact on student LD. The framework was produced as part of an institutional project to streamline LD provision across taught programmes and has achieved significant success in the twelve months since its launch.

\section{Learning Development in context - the UK perspective}

In 2011, Hilsdon explored student LD within the context of UK HE, declaring it critical to the student experience. Hilsdon reflects on the 'increasing currency' of LD and the use of the term to describe 'a complex set of multi-disciplinary and cross-disciplinary academic roles and functions' arguing that LD's distinguishing feature is in emphasising 'how students experience and make sense of learning activities and academic practices' but that its 'status and meaning remain contested' (2011, p.14). Indeed, Hilsdon highlights that the word 'development' is critical to emphasising the process of learning at university, thus dissociating the LD agenda from the more traditional 'deficit model' of study skills and skills acquisition (pp.16-17). Hilsdon considers the challenges associated in delivering LD within a progressively massified and diversified UK HE system with an increasingly large number of students from 'non-traditional' backgrounds and a focus on employability and graduate 
skills (pp.14-15). Hilsdon also addresses the dangers of associating LD with deficit discourses and highlights some of the challenges affecting its delivery. These include the provision of 'specialised support' and 'services' to students, which champions a culture of 'consumerism' and goes against embedding LD within mainstream teaching and learning. Similarly, Verity and Trowler (2011) write about the institutional context for LD, stressing its significance, the importance of giving it a 'voice beyond [its] immediate vicinity', and also providing cross-organisational opportunities to develop 'new practices and embed new resources within curricula' (pp. 245-6). The lessons learned about 'organisational architecture' are significant because they send important messages about how LD is seen as either 'a fundamental aspect of teaching and learning, or a remedial understanding where underperforming students need 'fixing' (p. 246). The accepted view, therefore, is that LD should be embedded within 'core teaching', that it should be developmental rather than remedial, and not challenged by 'bolt-on' provision (p. 246). Indeed, Barlow, Acroyd, and Phillips (2011) place emphasis on the importance of 'self-directed learning', 'learner autonomy', and promoting the concept of 'lifelong learning' as central tenets of student LD (pp.42-43).

Seven years on, more significant and far-reaching changes have occurred within and outside of the sector. These include the increase of student fees, in 2012, to more than $£ 9,000$ a year. The HERA (2017) now places a metrics-based approach at the heart of assessing value in HE. The TEF metrics assess university performance in teaching and learning based on student retention, degree outcomes, satisfaction (as measured by the National Student Survey, NSS) and the number of graduates in highly-skilled employment. At the same time, students with 'marginal learner identities' (Reay et al, 2010) such as those with disabilities, those from Black, Asian and Minority Ethnic (BAME) backgrounds and those from low socio-economic backgrounds, struggle to persist in HE and, if they do, are less likely to achieve a good honours degree (Zimdars et al, 2015). We argue that these changes threaten to unbalance the embedded and 'developmental' culture of student LD in teaching and learning. Governmental policy can potentially damage the good practice that has been emerging in universities in recent decades, one which seeks to understand each student's context and background, the way in which they learn, how they connect ideas and agendas, how they apply their knowledge and also the ways in which they reflect on their development. Here, we argue that the provision of LD is now more important than ever to the mission of UK HE but that to add real value and meaningful 
change LD needs to be more visible institutionally, positioned strategically, embedded within the curriculum and championed holistically across the whole university, as well as within disciplinary programmes. LD should therefore be at the forefront of interventions to encourage students to understand the purpose of $\mathrm{HE}$ and their role within it. It is only through a culture of strategic endorsement for LD that we can establish true staff-student partnership which guards against the language of consumerism (McIntosh and Cross, 2017) and encourage colleagues in HE to work with students as co-creators and coinvestigators of this important LD agenda.

\section{Learning Development at the University of Bolton, UK}

LD activities, broadly conceived, have always been a significant feature of student support at Bolton and they are central to the delivery of our Student Experience and Learning, Teaching and Assessment Strategies (2015-2020). These recognise the importance of LD and student-centred pedagogies for student retention, progression and success. Central to this is a recognition that initiatives developed to support our students must consider the diversity of our student body and be sensitive to their context. We are one of the most socially diverse HE institutions in the UK: many of our learners are mature (54\%), part-time (33\%) and commute into university from the local area (over $91 \%$ ). Over $74 \%$ are from the lowest-participation neighbourhoods, over $14 \%$ have a recognised disability or mental health issue and $34 \%$ are from BAME backgrounds. Many of these student groups experience recognised differences in degree outcomes (Zimdars et al, 2015) which means that integrated and embedded LD initiatives are particularly critical to the development of our student support infrastructure. As a result, the institution operates a model of Early Intervention and Transitional Support (EI) which comprises six elements to support student transition, progression and success. LD (The LEAP Programme) is one of these six critical elements in this infrastructure and sits alongside welcome and induction, personal tutoring and peer support (see Figure 1).

Figure 1. The Six Dimensions of the Early Intervention and Transitional Support (EI) Model 


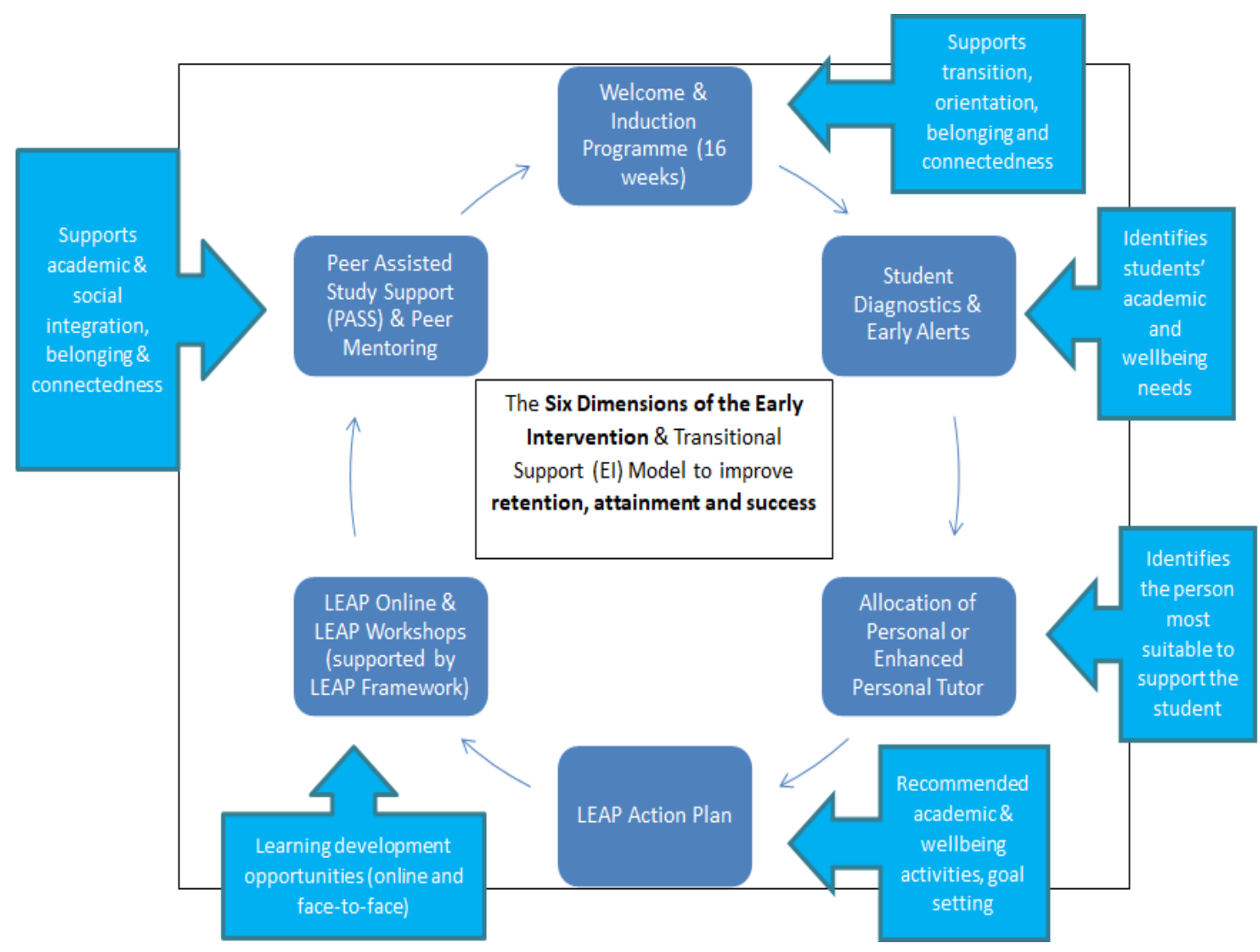

A Learning Development Working Group (LDWG) was established in 2015 to take forward institutional LD. The principal aim of the group was to re-conceptualise LD to ensure that it is a fundamental feature of the El approach. The objectives of the LDWG were to bring together various stakeholders from across the institution to: (1) carry out a systematic review, audit and evaluation of LD provision across the institution; (2) facilitate a shared understanding of LD and establish the most effective ways of providing embedded LD opportunities; (3) develop a culture of LD by exchanging ideas, developing expertise and sharing examples of best practice and (4) develop a LD framework which outlines the skills, knowledge and attributes required of students at different $\mathrm{HE}$ levels and modes of study. Key to this was a fundamental recognition that LD is developmental, contextual and critical to encouraging learner independence and autonomy.

The systematic review revealed significant differences in the design, delivery and terminology used to describe various LD initiatives across the institution. Whilst LD activities have always been delivered at Bolton in some shape or form, LD as a concept had been largely undefined and unarticulated. In 2015, LD activity was fractured and without coordination; there was undue focus on study skills over development, LD had no 
natural 'home' within the organisational architecture and there was also a disconnect between study skills modules, undertaken within the curriculum, and wider co-curricular student-engagement activities. As a result, LD was not recognised as a powerful strategic vehicle within which to promote learner autonomy, student transition and success. At that time there were three principal areas of LD activity in the institution, in addition to the delivery of programme-specific skills modules: (1) BISSTO (Bolton Interactive Study Skills Tutorial Online), an online LD programme in the library, (2) the Skills for Success Programme which delivered 1:1 academic writing and numeracy support and (3) the Bitesize Study Skills Programme, delivered by the Student Liaison Officers (SLOs) which offered one hour face-to-face workshops. The different names used to describe these interventions meant that they were not linked in the institution's consciousness and, as a result, were perpetuating a deficit approach. LD opportunities were not overtly visible to staff or students as being an integral part of student LD per se. Whilst these initiatives were well-regarded by students and staff familiar with them, they were seen as separate 'bolt-on' entities, delivered by separate teams and hidden rather than embedded. After a short consultation with staff and students, LEAP (Learning Excellence Achievement Pathway) was adopted as a universal term to recognise cross-institutional, embedded LD activity and work began to design and develop the LEAP framework.

\section{The development of the LEAP framework}

Whilst the ambition of LEAP is to connect and champion a mainstream culture of LD across the organisation, we also recognise that students identify primarily with their discipline (Thomas, 2012 and 2017) and that this is fundamental to realising their cohort and learner identity (Whannell and Whannell, 2015). Gibbs (2009, p.4) acknowledges the importance of embedding LD in a disciplinary context as there is 'little evidence that skills can transfer across contexts'. Moreover, he argues that as LD policy shifts to working with the 'whole institution, in ways that are aligned with other institutional efforts, as part of a broad strategy . . . efforts will need to be well conceptualised and backed up with convincing empirical evidence of impact' (Gibbs, 2009, p.9). This links with the longstanding debate concerning the distinction between 'core' and 'generic' study skills and their overall 'transferability' (Bennet et al, 1999, p.76) and also relates to the complex inter-relationship between the learning that takes place outside of the academy and the 
rapidly changing global environment. Bligh et al $(2010$, p.1) sum up the nature of the challenge that this presents:

HE involves attempts to allow students to gain new knowledge, understanding and skills. At the core ... are complex concepts, theories and ideas. . . Effective university teachers and students are constantly searching for better ways to both engage in teaching and facilitate new models of learning within these disciplines.

When developing the LEAP framework, it was therefore necessary to strike a delicate balance between the delivery of LD within and external to each academic discipline. It was also important to acknowledge that there are manifold opportunities for students to learn both inside and outside of the classroom and, indeed, the academy. These factors were taken into consideration when formulating the framework methodology and in the contextualisation and strategic coordination of the resulting LEAP programme. A core goal was for the framework to be used primarily within the curriculum, endorsed by academic colleagues and actively used in the classroom for the delivery of skills and LD activities at the discipline level.

The LEAP framework (Mclntosh and Barden, 2016) was developed systematically over a period of several months. It was then issued, in draft, to academic schools and professional support services for consultation. The LD audit was used as an initial baseline scoping exercise and the information gathered for that informed the overall framework methodology. This consisted of two principal activities: (1) an in-depth analysis of the content delivered in LD or skills modules situated within the curriculum (across all academic programmes), and (2) cross-referencing academic skills module data and analysis with the various co-curricular engagement and learning development opportunities available to students. The in-depth analysis of skills module content involved systematically analysing the skills module specification for over 40 academic programmes delivered across the institution. This exercise revealed the breadth of LD interventions delivered at the discipline and curricular level although, perhaps unsurprisingly, we found that there were also many commonalities across programmes such as academic writing, report writing, digital literacy and referencing. We used this information to create a map of LD topics and these were then cross-referenced with the co-curricular activities delivered 
in other areas of the institution, such as in the Library and Careers. Once these two main activities were complete we analysed the topics and identified distinct themes.

Four dominant categories emerged from this exercise and we used these to inform the four principal dimensions of the LEAP framework: (1) My Academic Development; (2) My Personal Development; (3) My Digital Literacy, and (4) My Student Engagement. Within these four dimensions we identified significant sub-dimensions (three in each, twelve in total) and, following that, used these sub-dimensions to identify the best fit for the different LD topics we had recognised in our analysis, which were then listed accordingly. The overall framework structure of the dimensions, sub-dimensions and topics, delivered at level HE3 and HE4, are illustrated in Figure 2. Further work was undertaken to identify the delivery of LD at different HE levels of study to chart the progressive development of skills over time. Separate topic lists, using the same dimensions and sub-dimensions, were identified for learners in HE5 and HE6. This helped to distinguish HE3 and HE4 LD activities from more advanced LD activities for students in higher years, such as dissertation writing.

\section{Figure 2. The four dimensions of the LEAP framework incorporating twelve sub- dimensions and LD topics at HE3 and HE4.}

\begin{tabular}{|c|c|c|c|}
\hline \multicolumn{4}{|c|}{ Welcome \& Induction (School \& Programme Level) } \\
\hline \multicolumn{4}{|c|}{ Learning Development Diagnostic (Skills Check) } \\
\hline & Learning Excellence Achievemen & vay (LEAP) Planning (with Personal Tu & \\
\hline My Academic Development & My Personal Development & My Digital Literacy & My Engagement \\
\hline $\begin{array}{l}\text { My Research Needs } \\
\text { - } \text { Library Induction \& Tour } \\
\text { - } \text { My Subject Librarian } \\
\text { - } \text { Discomic sources } \\
\text { - Using the Internet for Research } \\
\text { My Writing Techniques } \\
\text { - Note Taking } \\
\text { - Critical Thinking } \\
\text { - } \text { Reading Effectively } \\
\text { - Using Formal English } \\
\text { - } \text { Plagiarism } \\
\text { - Referencing } \\
\text { - Proofreading techniques } \\
\text { My Assessments } \\
\text { - Unlocking the question } \\
\text { - Essay Planning } \\
\text { - Report Writing } \\
\text { - Essay Writing } \\
\text { - Exam Preparation }\end{array}$ & $\begin{array}{l}\text { My Wellbeing } \\
\text { - Stress Management } \\
\text { - } \text { Mindfulness } \\
\text { - } \text { - Developing Self-Awareness } \\
\text { My Planning } \\
\text { - Preparing for University study } \\
\text { - Time Management } \\
\text { - Setting goals \& objectives } \\
\text { - } \text { Making the most of Year } 1 \\
\text { My Personal Effectiveness } \\
\text { - Learning Styles } \\
\text { - Presentation Skills } \\
\text { - Interpersonal Communication } \\
\text { - Problem-solving } \\
\text { - Teamworking } \\
\text { - } \quad \text { Retworking } \\
\text { - Excelling as a mature learner } \\
\text { - Cultural awareness }\end{array}$ & $\begin{array}{l}\text { My ICT } \\
\text { - } \quad \text { Email / IT Signup } \\
\text { - } \quad \text { MS Office } \\
\text { My Digital Footprint } \\
\text { - Social media: digital identity } \\
\text { - } \quad \text { Digital etiquette } \\
\text { - } \quad \text { Inttring started with Linkedin } \\
\text { - Social media to blogging } \\
\text { - } \quad \text { Digital rights \& responsibibilities } \\
\text { - Digital safety \& security } \\
\text { My Virtual Learning } \\
\text { - Introducing \& using Moodle } \\
\text { - Introducing \& using LEAP Online } \\
\text { - } \quad \text { Jurnitin } \\
\text { - } \text { App (My Bolton) }\end{array}$ & $\begin{array}{l}\text { My Future (Careers \& Employability) } \\
\text { - } \quad \text { Opportunity Awareness } \\
\text { - } \text { How to find a part-time job } \\
\text { - Career Planning } \\
\text { - } \quad \text { Psychometrics (Learning Styles) } \\
\text { - Careers Fair } \\
\text { - } \text { Employability Week } \\
\text { My Peer Learning } \\
\text { - Peer Mentoring } \\
\text { - Peer Assisted Study Sessions } \\
\text { (PASS) } \\
\text { My Student Experience } \\
\text { - Student Feedback \& Voice (UPSS) } \\
\text { - } \text { Bolton Award } \\
\text { - Volunteering } \\
\text { - Student Representation } \\
\text { - } \text { Ambassadors } \\
\text { - Worthwhile Wednesdays }\end{array}$ \\
\hline
\end{tabular}


Within the My Academic Development dimension, three sub-dimensions were identified: My Research Needs, My Writing Techniques, and My Assessments. These subdimensions reflect the apparent distinction made in curriculum delivery between research, writing and assessment. Highlighting these topics separately, but aligning them under the heading of Academic Development, ensures that the various components of academic development are visible and connected. Placing complementary topics alongside one another visually is designed to encourage students to consider and reflect, developmentally, upon the connections between different LD concepts. At the same time, these sub-dimensions provide a nominal structure, and flexibility, for students to explore LD opportunities, primarily within the classroom setting. The LEAP framework is sustainable and can develop and respond to the evolving, embedded delivery of LD over time - it is possible to add subject-level or disciplinary topics under these broad headings. This applies at both the institutional and local, i.e. discipline level. The topics listed under these sub-dimensions are not exhaustive and allow for further growth. Under the My Digital Literacy category, a distinction is made in the sub-dimensions between My ICT, My Digital Footprint and My Virtual Learning. This is to ensure that students are not only able to recognise the difference between developing the skills needed to use various digital technologies (e.g. email, various software packages and social media platforms), but also to develop sustainable habits which ensure that they are able to critically evaluate the use of such tools in their LD journey.

When identifying the dimensions, sub-dimensions and topics, our approach was informed by various external frameworks which promote learner independence and developmental activity, including the Citizen Scholar framework (Arvanitakis and Hornsby, 2016). This framework highlights student skills, attributes and proficiencies, emphasising the social mission of HE. Arvanitakis and Hornsby relate HE to practical life and highlight the pedagogical importance of creativity, critical thinking and problem solving. Importantly, they make a distinction between process-driven and design and systems thinking, encouraging the student to reflect on the process of their learning, not just the product. Our approach also considered and drew upon the categories in the SCONUL seven pillars of information literacy (revised, 2011) as well as the Higher Education Academy Flexible Learning Framework (HEA, 2015). We intended to create a thematic framework for students to explore the relationship between core topics and themes and to relate this to 
their experience in the classroom, and also outside of it. The framework is designed as a visible, informative tool for exploring LD, for organising resources and content which sit underneath it and focussing on the potential inter-relationship between common underpinning topics and themes. The recognised structures that inform LD practices in HE were therefore made more visible and accessible to staff and students. Reedy and Goodfellow (2014) in particular, endorse Hall et al's (2014) review of digital literacy frameworks and highlight the importance of guarding against approaches that reduce complex LD concepts into a series of 'discrete collections of skills and practices' (p.4). The LEAP Framework champions, visually, the fundamental pillars of LD within our university, but one of its key features is the opportunity for further exploration and contextualisation within the classroom. The framework is intended to be used and endorsed by academic colleagues at the embedded, discipline level, a practice which is designed to encourage all students to see the value of exploring their learning and experiences and connecting disparate themes and agendas in a way that helps them to construct new meaning and relate it to their subject knowledge and the conventions of their discipline.

One significant aim of the LEAP framework is to acknowledge the role of students as partners in their learning experience and this is apparent in the My Student Engagement dimension. The framework supports students to develop self-efficacy and capability in their chosen subject area. It also supports them to take advantage of the opportunities and experiences which will help them to develop as lifelong, autonomous learners and to pursue their chosen career path. The LEAP framework can assist students to navigate different points of transition into and across their degree programme, acknowledging independent learning and the proposition that students themselves have a key part to play in making their goals a reality. The framework is designed to empower students to tackle their academic and personal development in a pragmatic and meaningful way, by providing an organic and flexible structure within which to organise skills module content and related resource materials. It promotes the values of student ownership and partnership which is much discussed in the literature on student engagement (Trowler, 2010; Russel, 2015; Mclntosh, 2017; Mclntosh and Cross, 2017). The LEAP framework is designed to help students develop confidence and self-efficacy through the promotion of student engagement, peer learning and reflective practice, alongside academic development, all of which are essential to the creation of a vibrant and stimulating, applied learning environment. The framework is also designed to assist the university to showcase 
to students the multitude of opportunities available to create for themselves a unique, dynamic, stretching and challenging student experience. These factors were taken into consideration when the framework was designed and inform its ongoing development.

Although the underpinning dimensions and sub-dimensions, which inform structure of the LEAP framework, were mapped across different levels of study from HE3 to HE6 (as demonstrated in Figure 2), we identified the need for one holistic, visual model to represent the framework itself. This ensures that the framework is visible, identifiable and can be used to showcase and embed the different dimensions, sub-dimensions and categories within the curriculum. A visual model helps to engage staff and students in developmental conversations about LD across the institution. As Bligh et al (2010, p.1) argue, visual techniques must be used to support learning in HE and, in particular 'models ... play a critical role in supporting learning of complex ideas'. We therefore created a circular model for the LEAP framework which is accessible, engaging and gives parity to all four dimensions and twelve sub-dimensions. The circular representation, illustrated in Figure 3, is an icon of student LD across the institution. Embedded content and resources sit underneath the framework which scaffolds LD provision and is designed to reduce many of the barriers to independent learning that students face, particularly when they first transition into university (Kift and Nelson, 2005).

Figure 3. The circular representation of the LEAP framework. 

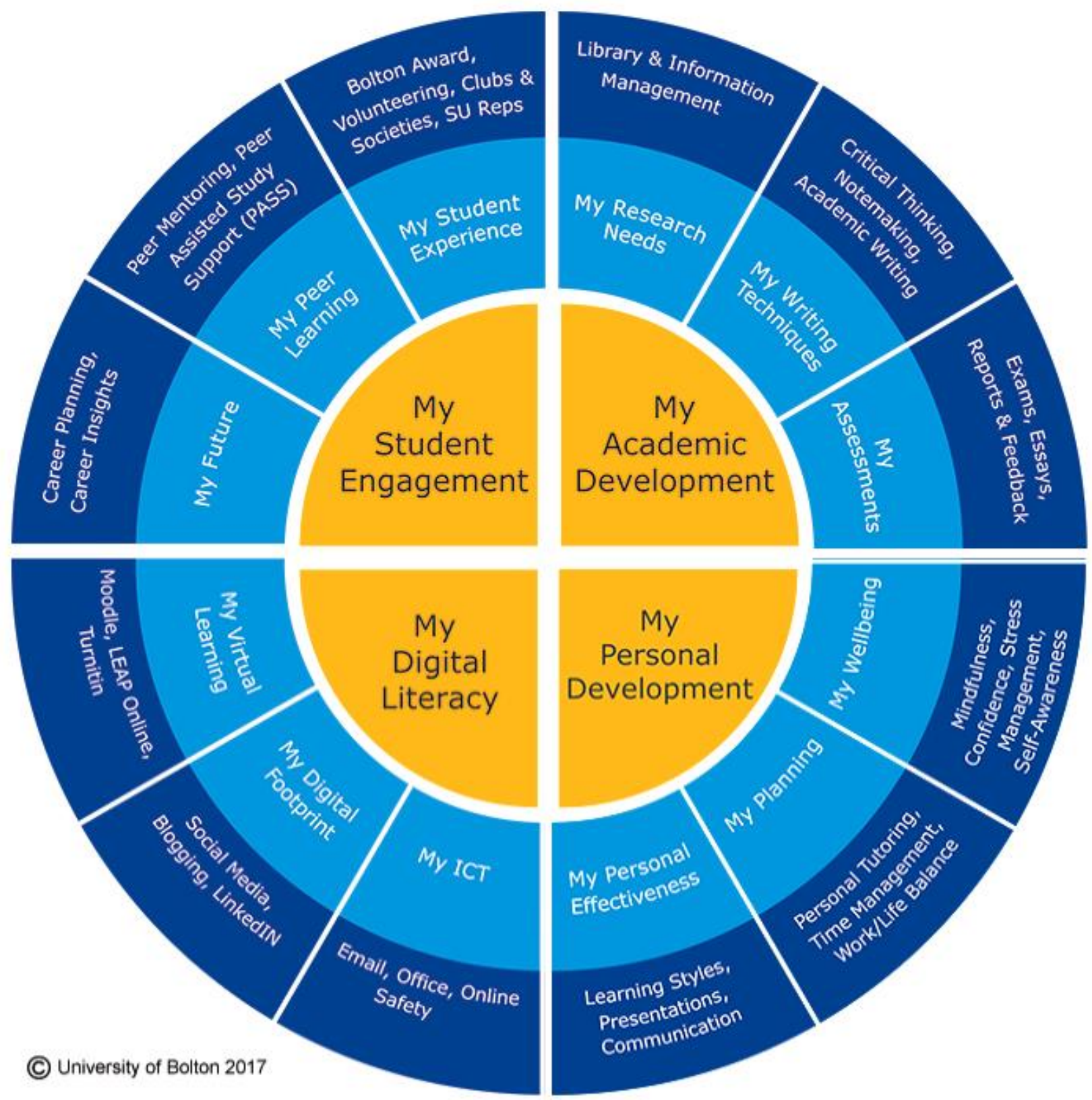

\section{The LEAP framework: an initial evaluation}

In the twelve months since the launch of the LEAP Framework we have been evaluating its effectiveness by investigating the use of LEAP Online (LO) within embedded, blended and classroom settings. LO is an interactive digital resource, built using instructional design measures, and used to promote student LD and information literacy: it is primarily accessed by academic colleagues and students within the classroom and in a blended environment, with Moodle (VLE) integration. Whilst BISSTO, the forerunner to LO, was well regarded by those who used it, it was disconnected from classroom learning and 
teaching activities, not embedded within timetabled module delivery and separate from Moodle. As part of the development process, work was completed to redesign BISSTO, align it with the LEAP framework and create an LD tool for embedded delivery of LD content and resources, led by academics within the classroom. LO was launched in September 2017 and it can be accessed here:

https://www.bolton.ac.uk/leaponline/Home.aspx. The circular representation of the framework is the principal interface for the LO portal where students are able to explore information literacy and access interactive LD modules. Badged assessments are used to track completion of LD activities and a full analysis of the data will be provided in a subsequent paper.

In addition to using the badged assessments to evaluate the effectiveness of LO, we devised two online questionnaires, one for staff and one for students in the first six weeks after launch. At that time there were 370 badge holders. These were surveyed about their LD habits and, in particular, their use of LO. 55 students responded to the survey with overwhelmingly positive feedback. $91 \%(n=50)$ of respondents had been recommended to use LEAP Online by their academics. $70 \%(n=38)$ of the students had been encouraged to earn the digital badges. $87 \%(n=48)$ enjoy collecting the badges. Most students stated that they completed the activities in each section and almost $80 \%(n=44)$ found them useful. We also captured qualitative comments. A thematic content analysis (Braun and Clarke, 2006; Bryman, 2008) of the free-text comments revealed that responses about the impact of LO fell into four dominant categories: (1) their LD behaviour and habits, (2) assessment of skills, (3) accessing help and support, (4) different LD contexts. In terms of (1) LD behaviour and habits many students $(n=28)$ stated that using LO had improved their academic skills and helped to build confidence. Several students requested further content and increased levels of difficulty. Of particular interest in the comments concerning LD behaviour and habits were the comments about the usefulness of the content and the impact that this had on their LD journey, particularly on the development of new competencies and skills. One student commented: 'the academic writing section has really helped with referencing and avoiding plagiarism' and another mentioned that LO has 'helped me to learn how to construct and plan an assignment, so it has benefitted me massively'. Students also commented on raised levels of self-awareness and reflection: 'it has made me more aware of my academic writing and referencing skills'. In terms of (2) assessment of skills, respondents were actively reflecting on their progress: 'building 
confidence, learning new skills, refreshing already acquired knowledge' and 'it has certainly helped in learning new skills and refreshing old ones'. Several $(n=5)$ commented that LO content had helped ease their transition into university: 'it has benefitted me with the transition from college to university study' and 'it has helped me to get back into studying again as it has been a while'. Students were also mindful of the increasing level of their skills development, an indication that they were interested in the actual process of their learning and enjoyed being 'challenged' by the material. Student respondents were also actively linking academic development with other forms of LD, including personal development such as mindfulness.

A key objective of LEAP was to coordinate LD activity and to improve the culture of LD across the organisation. In this regard students were also linking LD with (3) accessing help and support. Several respondents $(n=4)$ specifically mentioned that LO had helped them to understand how to seek help and support: 'it has made me more aware of the university and where to go for information'. Finally, LO has helped students to understand (4) different LD contexts at the university. Another key objective was to ensure that LD was embedded within the curriculum and delivered across recognised institutional boundaries. Several students mentioned the use of LO in class and many $(n=5)$ stated that they were using it to support their independent study habits: 'Completing the activities has allowed me to refresh my memory and learn without the traditional setting of a classroom'. The online and collaborative nature of the project has helped to position information literacy outside of the library per se and embedding it into mainstream curriculum delivery. Several students mentioned the level of accessibility and that the framework itself helped them to navigate opportunities. We recognise that, in targeting the students who already held badges, we were contacting learners who were already engaged in LD. That said, many students were directed to use the platform in the classroom as well as to self-refer to the tool outside of taught sessions. Nevertheless, a survey of their LD habits revealed the features that were important to them in the delivery of an integrated and engaging LD programme.

The LO staff questionnaire was developed and sent to the schools via Subject Librarians, it was completed by 14 members of staff. $88 \%(n=12)$ had actively encouraged their students to use LO and $69 \%(n=10)$ had actively encouraged their students to obtain the digital badges with $100 \%(n=14)$ agreeing that digital badges were a useful way of 
measuring engagement. The survey reinforced the themes generated from the student LO survey. Qualitative comments reflected the use of LO as a tool for transition into higher education and the impact of LO on student LD behaviour and habits, particularly concerning academic writing, confidence and referencing. Overall, the qualitative comments demonstrate that the objectives of the LEAP framework had been fulfilled. Namely, the easing of transition into university life; raising student awareness of their skills development; linking academic development with other forms of LD, including personal development such as mindfulness; improving accessibility to development opportunities; embedding LD within the classroom and the curriculum; coordinating LD activity to improve the culture of LD across the organisation.

\section{External Recognition}

The quality of the LEAP framework, and specifically of LEAP Online, has been recognised externally. In April 2018, four members of the LDWG received the national LILAC Digital Literacy Award. The Award recognises an innovative and high impact digital resource developed by a UK-based individual or group. The external judges commented:

This is well thought-through and the front end is visually appealing. It has a strong underpinning framework that enables students to develop their skills in a scaffolded way, with clear links to the curriculum and to employability. There is evidence of positive student engagement with the resource through badges gained and survey feedback.

\section{Conclusion}

This paper has outlined the development of the LEAP (Learning Excellence Achievement Pathway) framework at the University of Bolton, UK. The principal objectives of the LEAP framework were to map LD activity across the organisation and align disparate LD activity in the organisational consciousness, recognising that LD should be a key part of any embedded student success strategy. A key aim was to initiate a culture of LD across the institution, showcasing the variety of engagement opportunities available to students. The circular representation of the LEAP framework is visual, accessible and engaging. It has placed LD at the forefront of an early intervention (EI) approach at the university to support 
student transition and retention. Initial indications, principally data collected from the badged assessments and two online staff and student questionnaires, suggest that a culture of classroom-based and embedded student LD, underpinned by an institutional framework, is gaining traction in the institution as a key vehicle in which to promote student engagement, retention and success. Students are beginning to articulate changes to their behaviour and habits regarding LD, identifying sources of help and support as well as assessing their level of skill and understanding the different contexts in which LD takes place, both inside and outside of the classroom as well as external to the academy.

Work is now ongoing to continue developing and embedding the LEAP framework within the institution, most especially in blended and classroom settings. A subsequent paper will consider the impact and evaluation of LEAP in more detail. There are ambitions to conduct a longitudinal study to assess the impact of LEAP activities on student success, learner autonomy and independence and to align the badged assessment data with the EI model, particularly the development of academic tutoring and the use of learning analytics to assess engagement. Students and staff alike have expressed the need to develop subject/discipline level content. Increasing numbers of academic staff have requested to collaborate with us on the development of content for new sections. Academic advocacy has played a significant role in raising the profile of LD across the institution and it is our ambition that LEAP will continue to grow in response to both staff and student requirements.

\section{References}

Arvanitakis, J. and Hornsby, D. (2016) Universities, the citizen scholar and the future of higher education. London: Palgrave.

Barlow, A., Ackroyd, J., and Phillips, A. (2011) 'Is Learning Development Part of the Problem?', in Hartley, P., Hilsdon, J., Keenan, C., Sinfield, S., and Verity, M. (eds.) Learning Development in Higher Education. London: Palgrave.

Bennett, N., Dunne, E., and Carré, C. (1999) 'Patterns of core and genetic skill provision in higher education', Higher Education 37, pp.71-93. 
Bligh, B., Wiesemes, R., and Murphy, R. (2010) 'Introduction to the special issue on visual learning in higher education', International Journal of Media, Technology and Lifelong Learning 6(1), pp. 1-6.

Braun, V. and Clarke, V. (2006) 'Using thematic analysis in psychology', Qualitative Research in Psychology 3(2), pp. 77-101.

Bryman, A. (2008) Social Research Methods. Oxford: Oxford University Press.

Gibbs, G. (2009) 'Developing students as learners - varied phenomena, varied contexts and a developmental trajectory for the whole endeavour', Journal of Learning Development in Higher Education 1, pp. 1-12.

Hall, R., Atkins, L. and Fraser, J. (2014) 'Defining a self-evaluation digital literacy framework for secondary educators: the DigiLit Leicester project', Research in Learning Technology, 22:21440, no pagination.

Hilsdon, J. (2011) 'What is learning development?', in Hartley, P., Hilsdon, J., Keenan, C., Sinfield, S., and Verity, M. (eds.) Learning Development in Higher Education. London: Palgrave, pp. 13-27.

Higher Education Academy (2015) Framework for Flexible Learning in Higher Education. Available at: https://www.heacademy.ac.uk/system/files/downloads/flexible-learningin-HE.pdf (Accessed: 9 May 2018).

Kift, S. and Nelson, N. (2005) 'Beyond curriculum reform: embedding the transition experience', Higher Education Research \& Development Society of Australasia (HERDSA) Conference. Available at: http://conference.herdsa.org.au/2005/pdf/refereed/paper 294.pdf (Accessed: 18 October 2018).

Mclntosh, E. (2017) 'Working in partnership: the role of Peer Assisted Study Sessions in engaging the Citizen Scholar', Active Learning in Higher Education, Online First, pp. $1-16$. 
McIntosh, E. and Barden, M. E. (2016). The Learning Excellence Achievement Pathway (LEAP) - Striving for Excellence in Learning Development (Committee Document), Education Committee, The University of Bolton, February 2016.

McIntosh, E. and Cross, D. (2017) 'Who sets the agenda on student engagement?', Journal of Educational Innovation, Partnership and Change, 3(2), pp. 1-3.

NCIHE (1997) The Dearing report: higher education in the learning society. London: Her Majesty's Stationery Office.

Reay, D., Crozier, G., and Clayton, J., (2010) 'Fitting in' or 'standing out': working class students in UK higher education', British Educational Research Journal 36(1), pp.107-124.

Reedy, K. and Goodfellow, R. (2014) "You've been frameworked": evaluating an approach to digital and information literacy at the Open University', Journal of Learning Development in Higher Education, Special Edition: Digital Technologies, pp. 1-18.

Russel, E. (2015) 'What does partnership produce?', Journal of Educational Innovation, Partnership and Change, 1(2), pp. 1-2.

SCONUL Working Group on Information Literacy (1999, revised 2011) The SCONUL seven pillars of information literacy: core model for higher education. Available at: http://www.sconul.ac.uk/sites/default/files/documents/coremodel.pdf (Accessed: 5 May 2018).

Thomas, L. (2012) What Works? Student Retention and Success Programme (Report), York: Higher Education Academy. Available at:

https://www.heacademy.ac.uk/sites/default/files/what works final report.pdf (Accessed 12 January 2017).

Thomas, L. (2017) What Works 2? Supporting Student Success, Strategies for Institutional Change (Report), York: Higher Education Academy. Available at: 
https://www.heacademy.ac.uk/knowledge-hub/supporting-student-successstrategies-institutional-change (Accessed 11 April 2017).

Trowler, V. (2010) Student Engagement Literature Review, York: Higher Education Academy. Available at:

https://www.heacademy.ac.uk/resources/detail/evidencenet/Student engagement li terature review (Accessed 4 July 2017).

Verity, M. and Trowler, V (2011) 'Looking Back and Looking Into the Future', in Hartley, P., Hilsdon, J., Keenan, C., Sinfield, S., and Verity, M. (eds.) Learning Development in Higher Education. London: Palgrave, pp. 241-252.

Whannell, R. \& Whannell, P. (2015) 'Identity theory as a theoretical framework to understand attrition for university students in transition', Student Success, 6(2), pp. 43-52.

Zimdars, A., Sabri, D., Moore, J., Sanders, J., Jones, S., and Higham, L., (2015) Causes of differences in student outcomes (Report), Bristol: HEFCE. Available at: http://www.hefce.ac.uk/media/HEFCE,2014/Content/Pubs/Independentresearch/20 15/Causes,of,differences, in,student,outcomes/HEFCE2015 diffout.pdf (Accessed 8 May 2018).

\section{Author details}

Emily Mclntosh is Director of Student Life at the University of Bolton and a Principal Fellow of the Higher Education Academy (PFHEA). She has experience in leading, developing and implementing student-centred strategy, policy and operational change across the student lifecycle and leads on a number of cross-institutional student experience initiatives, as well as various aspects of teaching and learning activity. Emily's research interests include student success, transition, personal/academic tutoring, student resilience, student learning development and peer learning. 
Mary Barden has over 10 years' experience of working as an Academic Librarian and is currently eResources Librarian at the University of Bolton. She is a Senior Fellow of the Higher Education Academy (SFHEA). She has taken a leading role in in developing and enhancing the University's provision of information literacy and academic skills support. Mary was part of the small team at Bolton which won the LILAC Digital Literacy Award in 2018 for work on developing the LEAP Framework. 